ARID International Journal of Social Sciences and Humanities (AIJSSH) VOL.4, NO.7, January 2022

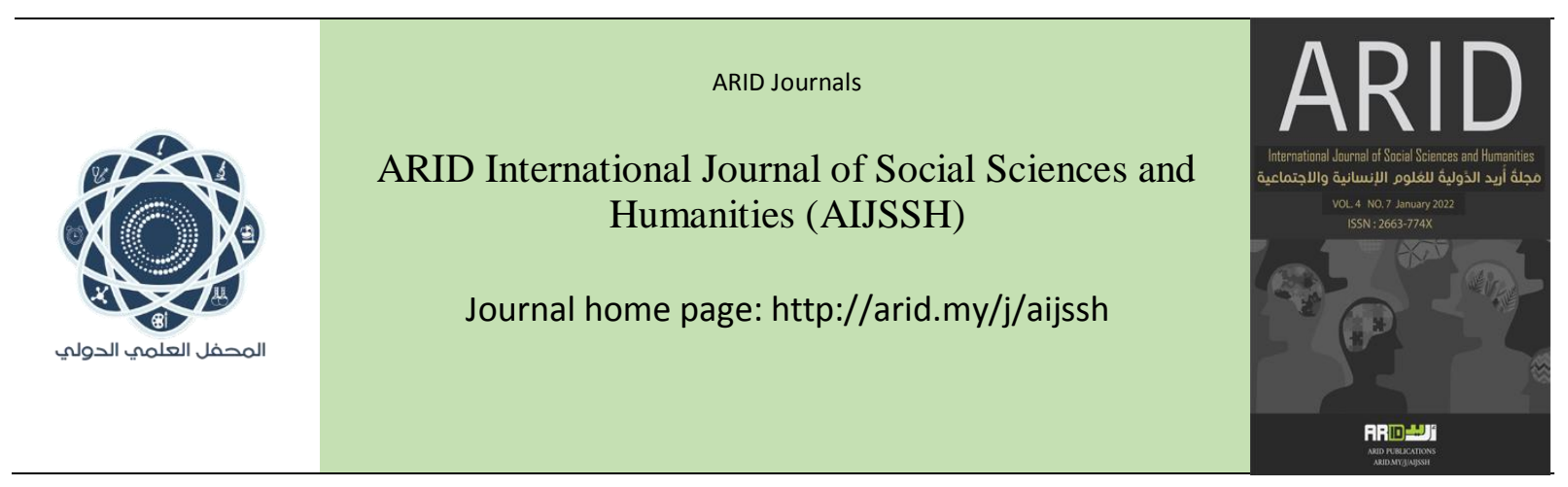

$$
\text { مَجلةُ أُريد الدَّوليةُ للعُلورج الإنسانية والإجتماعية }
$$

\title{
Conjunction, deduction and their effect on semantic cohesion Study in Alkhasaes book
}

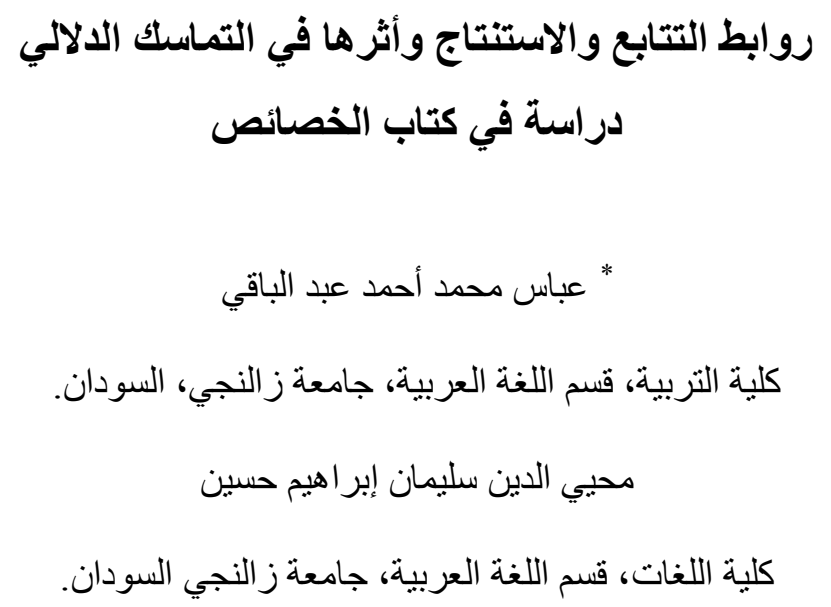




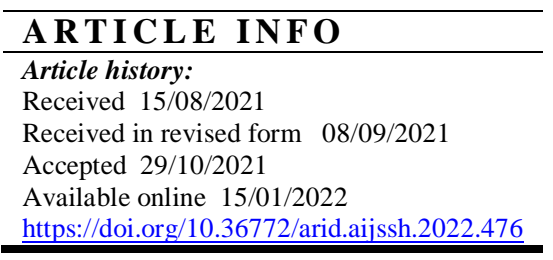

\begin{abstract}
Language is a coherent system that is subject to many relationships, and the sentence is the most important linguistic structure in this system. Words do not perform a function on their own. Rather, their function becomes clear when the parts capable of carrying the meaning are fused into the interconnected sentence and by the convergence of interconnected sentences a coherent text is formed. Therefore, modern linguistics has tended to study the necessity. Text beyond is a network of sentences linked by multiple linguistic relationships.

The aim of the research is to highlight the role of linkage in the construction and cohesion of the text by addressing the links of succession and conclusion for their clear effect on the coherence and harmony of the text. The importance of research appears through monitoring and following up the succession and conclusion links and showing how they are used in building texts.

The most prominent expected results are: It turns out that most of the deduction links consist of words and phrases, while most of the sequence links consist of letters and a few words. The researcher also found that succession links are always more used in texts than deduction links.
\end{abstract}

Key words: linking - connections - succession and deduction - text - semantic coherence. 


\section{الملخص}

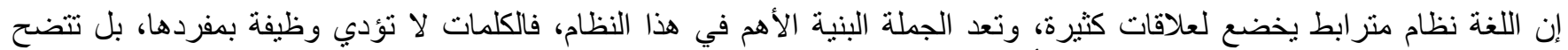

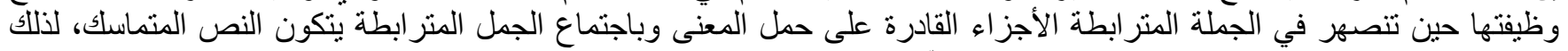

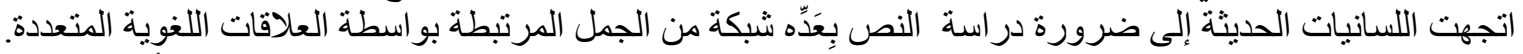

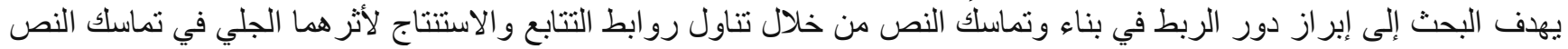

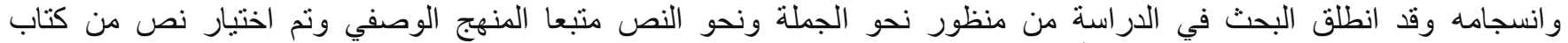

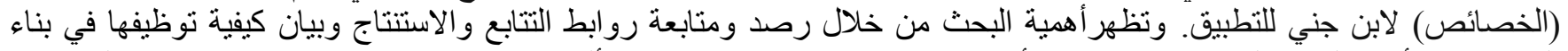

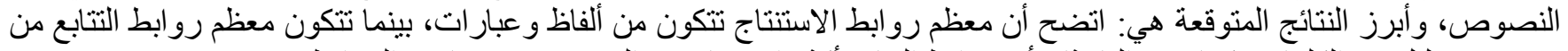
حروف، وقليل من الكلمات. كما وجد الباحثان أن روابط التتابع أكثر استعمالا في النص من غير ها من الروابط.

$$
\text { الكمات المفتاحية: التتابع ـ التماسك الدلالي ـ الاستنتاج ـ الربط ـ الرو ابط ـ النص. }
$$


درس النحاة موضوع الربط ضمن سردهم للأبواب النحوية المختلفة، وأثنار معظمه إلى أهييته في الكثف عن المعنى، ثم شهت الدراسات اللغوية تطوراً أفضى إلى الجمع بين الجملة والنص وتحليله والكثف عن مدى تماسكه وانسجامه. يهدف البحث إلى دراسة كيفية تحقيق أهم معايير النص الجيد (التماسك) من خلال بيان أثر روابط التتابع والاستنتاج في قوة التماسك بين عناصر النص، ومن غير شك أن الربط النحوي بين أجزاء الجملة يقوم بتوضيح وتفسير العلاقات النحوية بين الكلمات وجعل الجملة ذات معنى محدد وو اضح، ومن ثم تدخل في بناء النص و هي وحدة محكمة النسيج وجيدة السبك، وبناءً على ذلك يصبح النص كله متماسكا. إن المتلقي للنص بحاجة إلى تسلسل وتو الي الأفكار وصولا إلى الخلاصات، ويتم ذلك عبر روابط كثيرة تضمن سلاسة التتابع، وجودة النص، ومنطقية النتائج. ولتطبيق وظائف هذه الروابط تم اختيار نص من كتاب (الخصاص) وجاءت الدراسة على محورين: محور نظري بيَّن الدفاهيم والدصطلحات، ومحور تطبيقي نم فيه تحليل النص ورصد الروابط ودورها في تحقيق التماسك، وختمت الدراسة بذكر النتائج والمر اجع.

\section{المحور الأول: الربط أهميته ووسائله في اللغة العربية}

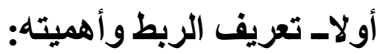

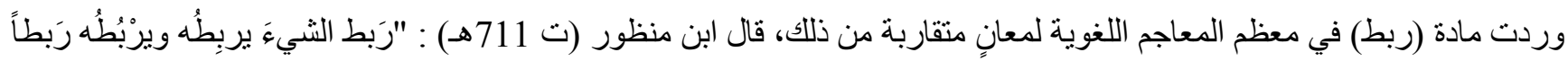

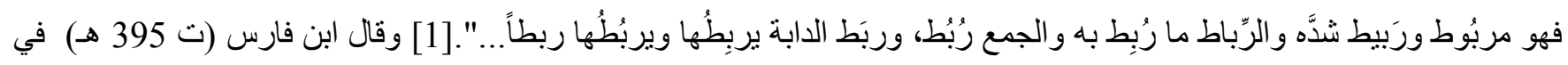
مادة (ربط): "الراء و الباء والطاء أصل و احد يدل على شُدِّ وثبات، من ذلك ربطنُ الثنيء أرْبطه...".[2] وقال الجوهري (ت 393هـ):

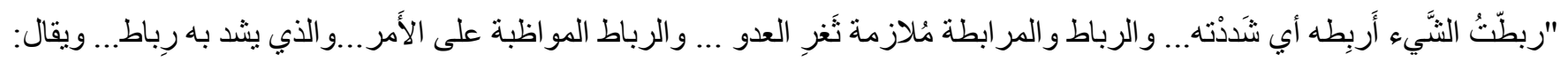

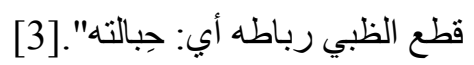
يتضح مما تقحم أن الربط في اللغة يدل على مطلق التقييد والجمع والثد والهنع والحب،، وهذه المعاني المتقاربة تقتضي اتصال الأطر اف بعضها بعضا. أما الربط في الاصطلاح فإنه يطلق على العلاقة التي تكون بين المفردات والجمل، وتجعل الأول متعلقا بالثاني فهو "ظاهرة تركيبية تنشأ. بين مجموعة من الكلمات بوسائل معينة، إمَّا ملفوظة أو ملحوظة، تتضافر مع قر ائن لفظية أخرى لأداء المعنى الوظيفي للتركيب، ولتحقق الغاية من اللغة وهي فهم المعنى، وهو قرينة تقوم على الاتصال بين المترابطين".[4] نخلص إلى أن الربط يعني إجادة نوظيف اللغة 
لتوصيل المعنى. وتُسمى الحروف والأدوات التي نربط بين أجزاء الجمل الروابط، قال عباس حسن: "الر ابط حرف أو ضمير يربط بين [5] [5رين... وتُعيِّن كون اللاحق منهما متعلقا بسابقه" إذن الروابط وسائل تجمع بين أجزاء الكلام، وتقيّدها بحيث تصبح منصلة في سياق واحد، والربط هو العلاقة القوية بين الكلمات و الجمل الناتجة عن دخول تللك الروابط في التركيب، قال الرضي (ت 648هـ): "الجملة في الأصل كلام مستقل فإذا قصدت جعلها جزءا من الكلام، فلابد من ر ابطة تربطها بالجزء الآخر...".[6] وظهر في اللسانيات الحديثة مصطلح الترابط الذي يطلق على العلاقة الدلالية الخاصة بين الجمل، ويُعَدُ التر ابط من مقومات وعناصر نماسك وانسجام النص.[7] تكمن أهمية استعمال وسائل الربط في التحام عناصر الفكرة التي تحملها الجملة؛ لأن الجملة تتألف من عدة ألفاظ تتضافر لتفيد معنى مقصودا، عليه فإن الكلمات لا تستعمل إلا مع بعضها، بل تخضع لعلاقات منظمة في إطار الجملة أي أن الجملة ليست كلمات أختيرت عشو ائيا ورصفت بعضها بجانب بعض بل تتماسك الكلمات فيما بينها بقوة، وهي نتاج فكر المتكلم أو الكاتب، وهذا يؤكد أن الربط يحافظ على بناء الجملة من التفكل ويكثف عن مدى تسلسل الفكرة وصلتها بالمعنى، ومن ثم تدخل الجملة في بناء النص وهي وحدة محكمة النسيج وجيدة السبك. إن الثرط الذي وضعه النحاة لإطلاق لفظة الجملة هو الإفادة، قال سييويه (ت 765 هـ): "ألا ترى أنك لو قلت: (إن يضرب يأتينا) و أشباه هذا لم يكن هذا كلاما". يقصد بلفظة (كلاما) جملة مفيدة. [8] و السبب الذي أخرج هذه الكلمات من حقل الجملة هو فقدانها للمعنى، وذلك لأنها؛ افتقرت إلى الربط بين عناصر ها فإذا فُقد الربط فُقد المعنى. وينص دي سوسير على أن: "الجملة أحسن نموذج يمثل التركيب في السياق...". [9] و عليه تُعدُ الجملة السليمة المعبرة اللبنة الثانية بعد الكلمة في بناء النص وتركيبه، و عليها المرجع في حمل المعنى والفكرة؛ لذلك ينبغي أن تكون واضحة الفكرة، تامة المعنى، مر اعية لقو اعد النحو وأصول الخطاب العربي أسلوبا وكتابة ومر اعاة للسياق ولن تكون الجملة بهذه الجودة إلا إذا رُوعِي فيها الربط السليم. وقال ابن السراج (ت 316هـ): مشير ا إلى أهمية الربط بالحروف: "واعلم أن الحرف لا يخلو من ثمانية مواضع: إما أن يدخل على الاسم وحده مثل: الرجل، أو الفعل وحده مثل: سوف، أو لربط اسم باسم، نحو: جاءني زيد وعمرو ... أو ليربط جملة بجملة..." [10] فالربط إذن قرينة لفظية ومعنوية مهمة تعمل على تماسك التراكيب العربية وتجنبها اللبس في مضامينها ودلالاتها. [4] لذلك يمكن عدَّ الربط مقوما فاعلا من مقومات التو اصل اللغوي الجيد. كما يقوم الربط السليم بين أجزاء الجملة بنوضيح وتفسير العلاقات النحوية بين الكلمات، ففي الجملة الفحلية يرتبط الفعل بفاعله، وفي الاسمية يرتبط المبتدأ بخبره، ويتمثل هذا في علاقة الإسناد التي تفسر ارتباط الركنين الأساسيين (المسند إليه والمسند)، كما يمتد أثر الربط؛ ليوضح علاقات نحوية أخرى إذ يرتبط الجار بالمجرور والمضاف بالمضاف إليه، والصفة بموصوفها، والحال بصاحبها، 
و التوكيد بمؤكده، والمعطوف بالمعطوف عليه. يشكل الربط السياج القوي الذي يحمي المعنى من التداخل و الخفاء و الفساد، ويحافظ على وحدة اللغة وسلامنها وسلاستها، ويمكنها من أداء وظيفتها الأساسية المتمثلة في إقامة التو اصل اللغوي السليم بين الأفر اد و الجماعات.

\section{ثانيا- وسائل الربط وأنواعه في العربية:}

بحث معظم العلماء باللغة قديما وحديثا قضية الربط، وتحدثوا عن الوسائل التي_تستعلها اللغة في الربط وقد جاء حديث القدماء عن الربط مُفََّقا في الأبو اب النحوية مثل: باب العطف و التوكيد والثرط وحروف الجر ومعانيها وباب الضمائر ونحوها، أي أنهم لم يفردوا درسا خاصا للربط ووسائله إلا أنهم نبهوا إلى أهميته من خلال ذلك التناول المتفرق. [11] تحدث السيوطي (ت 911هـ) عن الربط قائلا: "الحروف تدخل إمَّا للربط أو للنقل أو للتأكيد... وأمَّا حروف الربط فهي: حروف العطف وأدوات الثرط و التفسير والجواب والإنكار و المصدر...لأن الربط هو الداخل على الثيء لتعلقه بغيره". [12] وأثار ابن السراج (ت316هـ) إلى بعض أدوات الربط قائلا: "حروف الجر تصل ما قبلها بما بعدها فتوصل الاسم بالاسم والفعل بالاسم... فأما إيصالها الاسم بالاسم كقولك: الدار لعمرو...". [10] وقال ابن يعيش (ت 643هـ): "إنَّ (ذو) دخلت وصلة إلى الأسماء و الأجناس...، و(أبْ) وصلة إلى نداء ما فيه الألف و اللام، واسم الإشارة وصلة إلى نقل الاسم من تعريف العهد إلى تعريف الحضور...". [13] يريد ابن يعيش بقوله (وصلة) رابطة. وقد وصلت إلينا مؤلفات قديمة كثيرة ومشهورة فصلت في الربط وحروفه أبرز ها وأشهر ها كتاب (مغني اللبيب) لابن هثام (ت761 هـ) خاصة في حديثه عن الضمير. [14] وتعدُّ حروف الجر وحروف العطف وحروف الشرط وحروف الجواب والتفسير والإنكار، والضمير واسم الإشارة، واسم الموصول أظهر أدوات الربط عند القدماء.

أمَّا في العصر الحديث فإن الدراسة التي قدمها تمام حسان في كتابه (اللغة العربية معناها ومبناها) عن الربط وأهميته ووسائله ومواضعه في العربية، تعدُّ من أكثر الدراسات نضجا وأوضحها منهجا في معالجة قضية الربط، وقد حدد نمام حسان أدوات الربط وحصر ها في الآتي: الضمير و الحرف، إعادة اللفظ، إعادة المعنى، اسم الإشارة، دخول أحد المترابطين في عموم الآخر، أمَّا مواضع الربط فهي: الموصول وصلته، المبتدأ وخبره، الحال وصاحبه المنعوت ونعته، الثرط وجوابه، القسم وجوابه. [4] قدَّم تمام حسان نموذجا كاملا لنظام الربط في العربية، الأمر الذي كثف عن سعة مفهوم الربط لدى المحدثين باعتباره قرينة لفظية تُعِيْن الدارس على تحليل التراكيب تحليلا لغويا شاملا، دون الاقتصار على مجرد الربط بين كلمة وأخرى أو ربط جملة بجملة، وبذلك فتح المحدثون ميدانا أوسع للتطبيق اللغوي الكامل لنظام الربط. وبناء على ما تقدم من ذكر أدوات الربط عند القدماء والمحثثين يمكن أن نجمع الربطو أدواته تحت الأنواع التالية، مع شيء من الاختصار : أولا- روابط العطف: و هي (الواو) وتفيد الجمع و المشاركة مثل: ذهب سعيد ورفيقه، و(الفاء) وتفيد الترتيب و التعقيب دون مهلة، مثل: دخل المعلم فالمدير، و (ثخ) وتقيد الترتيب مع التراخي في الزمن كقولك: صليت المغرب ثم العشاء و(أو) ووظيفتها بيان التخيير و التقسيم 
و الثك، كقولك: أنفق در هما أو درهمين، و(أم) ووظيفتها بيان المساواة كقولك: أحب أمي سواء كانت قاسية أم رحيمة و(بل) وتوضح الإضر اب أي نفي ما قبلها و إثبات ما بعدها، نحو: حضر محمد بل أحمد، و(لكن) وتبين الاستدارك و التعارض، نحو: ماحضر الإمام لكن نائبه، و (لا) وتفيد نفي ما بعدها و إثبات ما قبلها نحو: أكلت تفاحا لا عنبا، و(حتى) وتفيد انتهاء الغاية، مثل: استمر العمل حتى المساء. ثانياـ روابط التتابع: ومنها: أيضا، بحيث، بالإضافة إلى، زد على ذلك، فاء الجزاء، وكلها تفيد وصل الكلام بعضه ببعض، كقولنا: حدثنا الخطيب عن فضل الصدقة بالإضافة إلى حسن الخلق ونبهنا أيضا إلى عاقبة الكذب. ثالثاـروابط التفسير: وهي: أي، أقصد، أعني، بمعنى، معنى ذلك، ووظيفتها الثرح و التوضيح مثل: قرأت كتابا عن الجيولوجيا أي: علم الأرض.

رابعا- روابط الاستشهاد والتمثيل: ومنها: مثلا، نحو، كما، كتلك، مثال، على، وتؤدي وظيفة ضرب المنل لتقريب الصورة ودعم الفكرة، نحو: ازدهرت في العصر العباسي علوم كثيرة مثل: اللغة والنحو، و عرفت فنون كثيرة نحو: الرسم والنحت. خامساـ روابط التفصيل: ومنها: أمَّا، من جهة، تارة، مرة، كقوللك: الإنسان مختلف الأحو ال فمرة يحزن وتارة يفرح. سادساـ روابط الاستنتاج: وتضم ألفاظا كثيرة أبرزها: إذن، لذلك، لذا، من هنا، بناء عليه، لأجل ذللك، وتفيد تقديم النتيجة بعد التحليل وتقديم الأدلة، مثال: نظمت وقتك، ورتبت مهامك، إذن تسعد في حياتك. سابعا- روابط السببية: وهي: لام التعليل، فاء السببية، كي، لأن، ووظيفتها التفسير وربط السبب بالنتيجة، كقولك: ياليتني كنت معهم فأربح ربحا كثير ا.

ثامناـ روابط الاستثناء: و هي: إلا، خلا، ماعدا، حاثنا، غير، وتستخدم لاستبعاد المستثنى من الحكم، نحو: فذخلو ا عليه إلا قليلا منهم. تاسعاه روابط الظرفية: وهي: أمام، خلف، فوق، تحت، بين، وقت، ووظيفتها تحديد الزمان و المكان، وتسلسل السرد وتحريك الوصف، و إيحاء الصورة، مثل: سافِر حيث تكون مطمئنا، جلس الطلالب أمام النافذة.

\section{المحور الثاني: روابط التتابع والاستنتاج والتماسك الدلالي}

\section{أولا- مفهوم التماسك الدلالي:}

يمثل المعنى المحور الأساس الذي تدور حوله معظم الدراسات اللغوية؛ لأنه يبحث عن المعنى لذلك فإن التماسك الدلالي في أي بناء لغوي له أهية بالغة فهو الذي يجعل أجزاء الكلام منر ابطة منآلفة حاله حال البناء المحكم الأجز اء. [15] وتعني كلمة (تماسك) في اللغة: التر ابط و القوة و الثّد و الضبط. [2] أما كلمة الدلالة فقد قال ابن منظور : "دله عليه سدده إليه.... والدليل: ما يُسْتدل به و الدليل: الدال...". [1] وقال ابن فارس:"...دللتُ فلانًا على الطريق. و الدليل: الإمارة في الثيء وهو بيّن الدَّلالة والدّّلالة...[2] إذن المعنى الجامع لكلمة (الدلالة) يتمحور حول: العلامة والإشارة والإرشاد والتسديد والإبانة والدليل الذي يقود إلى الهدف المنشود. والدلالة اللفظية هي ما 
يقتضيه اللفظ عند إطلاقه، أو ما يعنيه اللفظ ويُقصد به، أي فهم المعنى من اللفظ. [16] يتبين من المعنى اللغوي لكلمتي (التماسك) و (الدلالة) أن معنى التماسك الدلالي هو الترابط المعنوي في النصوص المختلفة. أما معناه الاصطلاحي فنجده واضحا عند الجرجاني (ت 471هـ) حين قال: "و اعلم أن مِمَّا هو أصل...في توخي المعاني التي عرفت أن تتحد أجز اء الكلام ويدخل بعضها في بعض، ويشتد ارتباط ثان منها بأول، وأن يُحتاج في الجملة إلى أن تضعها في النفس وضعا واحدا، وأن يكون حاللك فيها حال الباني يضع بيمينه ههنا في حال ما يضع بيساره هناللك...". [17] وقد لقِي التماسك الدلالي في العصر الحديث اهتماما بالغا وكثر الحديث عن مفهومه و آلياته

وضو ابطه و لا أدَلُّ على ذلك من كثرة المصطلحات الدالة عليه عند المؤلفين مثل: الحبك، الاتساق، الانسجام، السبك، الالتحام. [18] وقد اشترط معظم المحدثين توفر التماسك الدلالي لصحة النص، يرى جون ليونز: أن النص لابد أن يضم مجموعة مميزة من الخصائص التي تفضي إلى التماسك و الانسجام. [19] ويربط فاينرش بين ترابط أجز اء النص وفهمه قائلا: "النص وحدة كلية منر ابطة الأجز اء متلاحمة العناصر وتشابك هذا النسيج اللغوي داخل الوحدة الكلية للنص يؤدي إلى فهمه فهما معقو لا". [20] بينما النص عند هاليداي، ورقية حسن: "بنية من نمط مختلف، إنه يشكّل وحدة دلالية لا من حيث الثكل بل من حيث المعنى". [21] كما أشنار بعضهم صر احة إلى التماسك في النصوص فقال: "إن النصوص تكوين بسيط من الجمل تنشأ بينها علاقات تماسك". [22] وقال محمد العبد عن النص: " هو كلية متر ابطة الأجز اء، فالجمل يتبع بعضها بعضا وفقا لنظام سديد بحيث تسهم كل جملة منها في فهم الجملة التي تليها فهما معقو لا، كما تسهم الجملة التالية من ناحية أخرى في فهم الجمل السابقة عليها فهما أفضل". [23] وقال استيتة: "النص محكوم بمجموعة من العلاقات اللفظية و الدلالية بين أجز ائه بأن تكون هذه الأجزاء متماسكة متلاحمة". [24] أكدت المفاهيم المذكورة - مع اختلاف توجهات أصحابها- على أساس واحد ملازم لنصية النص هو تماسك أجزائه دلاليا ليصبح وحدة كلية متسقة ومتماسكة، ويتم ذلك التماسك على مستوى البنية العميقة من خلال الروابط اللغوية والمعنوية الكثيرة، ومن بينها روابط التتابع و الاستنتاج.

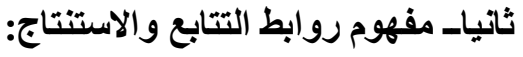

1/ روابط التتابع: قيل في معنى تبع: تَنِعَ الشيء تبعًا وتباعًا، وتبعت الثيءَ: سرتُ فِي إِثْرِهِ وتتبعه قفَّاه وتطلبه متبعا له...[1] وقال سيبويه (ت 765هـ): "وتبعت القوم تَبَعَا وَتَبَاعَةً، بالفتح إِذا مشيت خلفهم وتابع عمله وكلامه: أتقنه و أحكمه...وهو تبيع للكلام إذا أَحكمه. ويقال: هو يتابع الحديث إذا كان يسرده، وقيل: فلانٌ متتابع العلم إذَا كان علمه يشاكل بعضه بعضا لا تفاوت فيه، وغصن منتابع إذا كان مستويا لا أُبَنَ فيه". [8] إنن تتابع الكلام معناه إحكامه و إتقانه ليكون منو ازنا لفظا ومعنى، ويتحقق ذلك من خلال توفر ألفاظ و عبار ات معينة يُطلق عليها رو ابط التتابع و على منتج النص أن يحسن توزيع واستخدام تللك الروابط حتى ينتج نصا منماسكا، و هي كثيرة أشهر ها: أــ روابط العطف: (الواو، الفاء، ثم، أو أم، بل، لكن، لا، حتى). 


$$
\begin{aligned}
& \text { ب - رو ابط التفسير : (أي، أقصد، أعني، بمعنى، معنى ذللك، على نحو...). } \\
& \text { ج - رو ابط الاستشهاد و التمثيل: (مثنا، نحو، كما، كذلك، مثال...). } \\
& \text { د - روابط التفصيل: (أما، من جهة، تارة، مرة...). } \\
& \text { هـ رو ابط الاستثناء: (إلا، خلا، ماعدا، حاشا، غير، سوى...). } \\
& \text { وـ-روابط الظرفية: (أمام، خلف، فوق، تحت، بين، وقت...). } \\
& \text { ز-روابط الإضافة: (أيضا، بحيث، بالإضافة إلى، زد على ذللك، فاء الجزاء...). }
\end{aligned}
$$

ح - روابط أخرى: 1ـ اختيار المفردة المناسبة والموضوع يؤدي إلى بيان الفكرة وانسجام الدلالة وحمل المتلقي على المتابعة. 2ـ التكرار اللفظي أو المعنوي يثد المتلقي ويجدد نشاطه ويحفزه للمواصلة في التلقي. 3ـ التناسب بين الكلمات وزنا وطو لا يضفي على النص مسحة إيقاعية لطيفة جاذبة.

تعمل كل هذه الروابط على بناء شبكة متماسكة بين أجزاء النص من خلال وظائفها المختلفة المتمثلة في: وصل الكلام والجمع و المشاركة و الترتيب و المساو اة والتخيير و التقسيم ونفي الثكك والثرح و التوضيح وضرب المثل لتقريب الصورة وكثف المعنى. و إذا تأملنا هذه الوظائف نجد أنها تمثل رو ابط دلالية مهمة من شأنها أن توفر التتابع الجيد للمتلقي، و التماسك القوي للنص، وتسعى إلى الكثف عن التنظيم الداخلي لبنية النص الدلالية الخاصـة. 2/ روابط الاستنتاج: نتج: نتج الثيءَ نو لاّه حتى أنى نِتاجه، نتج الثيءُ عن الثيءِ: تسبّب عنه. استتنج الثيء استنبطه ووصل إليه بعد تفكير. [1] إذن الاستتناج استنباط واستدلال؛ أي انتقال الذهن من قضية مسلمة إلى قضية أو قضايا أخرى ناتجة عنها مع إقامة الدليل لإثبات المطلوب. ويأتي الاستتناج بعد التتبع الدقيق للنص واستقر ائه ومعرفة معناه ومن ثم الوصول إلى النتيجة أو الحكم، وعلى المستوى

$$
\text { اللغوي يعتمد الاستنتاج على عدة روابط منها: }
$$

أ_-رو ابط السبيية و التعليل: (لام التعليل، فاء السبيية، كي، لأن، و السبب في ذلك، قابله لكي، من أجل أن لكيلا وتسبب عن كذا،...). ب - روابط التلخيص: (وخلاصة القول، وباختصار، ونوجز القول، ويتلخص الأمر في...). ج - روابط الاستطر اد: (فضلاً عمَّا سبق، بالإضافة إلى هذا، يضاف إلى ذلك، كما أنَّ...). د - روابط الاستدر الك: (و على أي حال، ومهما يكن من أمر، و على الرغم من، فإن...) ه - رو ابط النتيجة وتضم ألفاظا كثثرة: (إذن، لذا، من هنا، بناء عليه، ولهذا، ونتيجة لذلك، و هكذا نستتنج ما يلي ويتضح مما، كل ذلك بسبب الاعتقاد أن، ويعود الأمر إلى، ويفهم من هذا الطرح...). وتفيد تقديم النتيجة بعد التحليل وإقامة الأدلة، وعليه فهي تربط بين الأسباب و المسببات ربطا قائما على الاستدلال والاستتباط والحجة، ومن ثم فإنها تعمل على الكثف عن مدى تماسك وتآزر أجز اء النص. 


\section{باب القول على أصل اللغة إلهام هي أم اصطلاح}

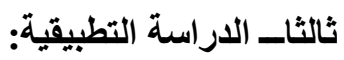
قال ابن جني: "هذا موضع محوج إلى فضل نأمل، غير أن أكثر أهل النظر على أن أصل اللغة إنما هو نواضع واصطلاح، لا وحي

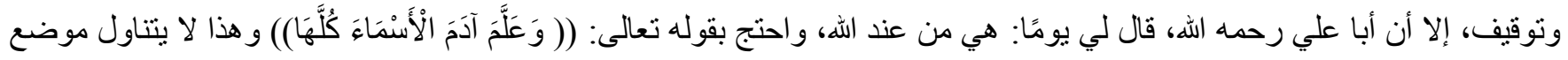
الخلاف، وذلك أنه قد يجوز أن يكون تأويله: أَقْرَر آدم على أن واضع عليها و هذا المعنى من عند الله سبحانه لا محالة فإذا كان ذلك محتملًا غير مستنكر سقط الاستذلال به. وقد كان أبو علي ـرحمه الهـ- أيضًا قال به في بعض كلامه، وهذا أيضًا رأي أبي الحسن على أن أبا الحسن لم يمنع قول من قال: إنها تواضع منه، على أنه قد فُسر هذا بأن قيل: إن الله سبحانه عَلَّمَ آدمَ أسماءَ جميع المخلوقات بجميع اللغات العربية والفارسية، والسريانية و العبر انية والرومية وغير ذلك من سائر اللغات؛ فكان آدم وولده ينكلمون بها ثم إن ولده تفرقو ا في الدنيا، وعَلق كل منهم بلغةٍ من تلك اللغات فغلبت عليه واضمحل عنه ما سوا ها لبعد عهدهم بها و إذا كان الخبر الصحيح ـهكذا يقولـ قد ورد بهذا؛ وجب تلقيه باعتقاده والانطو اء على القول به. فإن قيل فاللغة فيها أسماء و أفعال وحروف، وليس يجوز أن يكون المُعَلَُّ من ذلك الأسماء دون غير ها مما ليس بأسماء، فكيف خص الأسماء وحدها؟ قيل: اعتد ذلك من حيث كانت الأسماء أقوى القبل الثلاثة ولا بد لكل كلام مفيد من الاسم، وقد تستغني الجملة المستقلة عن كلّّ واحٍٍ من الحرف والفعل؛ فلما كانت الأسماء من القوة والأولية في النفس و الرتبة على ما لا خفاء به؛ جاز أن يكتفى بها مما هو نال لها ومحمول في الحاجة إليها و هذا كقول المخزومي: الله يعلم ما تركت قتالهم حتى علوا فرسي بأنثقر مزبد

أي: فإذا كان الله يعلمه فلا أبالي بغيره سبحانه، أذكرته واستشهته أو لم أذكره ولم أستشههه، ولا يريد بذلك أن هذا أمر خفي، فلا يعلمه إلا الله وحده، بل إن ما يحيل فيه على أمر واضح وحال مشهورة حينذذ متعالمة، وكللك قول الآخر : الله يعلم أنا في تلفتنا يوم الفراق إلى

$$
\text { أحبابناصور }
$$

وليس بمدعٍ أن هذا باب مسنور، و لا حديث غير مشهور حتى إنه لا يعرفه أحد إلا الله وحده، وإنما العادة في أمثاله عموم معرفة الناس به؛ لفشوه فيهم، وكثرة جريانه على ألسنتهم. قيل: هذا و إن جاء عنهم فإن إظهاره أنسب عندهم وأعذب على مستمعهم، ألا ترى إن فيه إيذانا من صاحبه بعجزه عنه وعن ستر مثله، ولو أمكنه إخفاؤه والتفاعل به لكان مطيقا له مقتنرا عليه، وليس في هذا من التغزل ما في الاعتراف بالبعل به، وخور الطبيعة عن الاستقلال بمثله ألا ترى إلى قول عمر بن أبي ريعة: فقلت لها ما بي من ترقب ولكن سري لا يحمله منلي وكنللك قول الأعشى: *وهل تطيق وداعا أيها الرجل* وقول الآخر : ودعته بدموعي يوم فارقني ولم أطق جز عا للبين مد يدي وأمر في هذا أظهر، وشوا هده أكثر وأسير. 
ثم لنعذْ فلنقلْ في الاعتلال لمن قال بأن اللغة لا تكون وحيًا، وذلك أنهم ذهبو ا إلى أن أصل اللغة لا بد فيه من المواضعة، قالوا: كأن يجتمع حكيمان أو ثلاثة فصاعدًا، فيحتاجوا إلى الإبانة عن الأشياء المعلومات، فيضعو الكل واحد منها سمةً ولفظًا، إذا ذُكر عُرف به ما مسماه، ليمتاز من غيره، وليغني بذكره عن إحضاره إلى مَر آة العين فيكون ذلك أقرب وأخف وأسهل من تكلف إحضاره، لبلوغ الغرض في إبانة حاله، بل قد يحتاج في كثيرٍ من الأحوال إلى ذكر ما لا يمكن إحضاره ولا إدناؤه كالفاني، وحال اجتماع الضدين على المحل الواحد، كيف يكون ذلك لو جاز و غير هذا مما هو جار في الاستحالة والبعد مجر اه. فكأنهم جاءوا إلى واحد من بني آدم، فأومَئوا إليه، وقالو ا: إنسان إنسان إنسان، فأيَّ وقت سُمع هذا اللفظ عُلم أن المر اد به هذا الضرب من المخلوق، وإن أرادوا سمة عينه أو يده أشاروا إلى ذلك فقالو ا: يد، عين، رأس، قدم، أو نحو ذلك، فمتى سمعت اللفظة من هذا عرف مَعْنُهُهَا، وهلم جرَّا، فيما سوى هذا من الأسماء والأفعال و الحروف، ثم للك من بعد ذلك أن تتقل هذه المو اضعة إلى غير ها فتقول الذي اسمه إنسان فليجعل مكانه مرد، و الذي اسمه رأس فليجعل مكانه سر، و على هذا بقية الكلام. وكذلك لو بدئت اللغة الفارسية، فوقعت المواضعة عليها؛ لجاز أن تتقل ويولد منها لغات كثيرة، منها: الرومية و الزنجية و غير هما. و على هذا ما نشاهده الآن من اختر اعات الصناع لآلاتِ صنائعهو من الأسماء كالنجار و الصائغ والحائك و البناء وكذلك الملاح. قالوا ا: ولكن لا بد لأولها من أن يكون متو اضعًا بالمشاهدة و الإيماء، قالو ا: والقديم سبحانه لا يجوز أن يوصف بأن يواضِحَ أحدًا من عباده على شيء؛ إذ قد ثبت أن المو اضعة لا بد معها من إيماء وإثـارة للجارحة نحو المومئ إليه والمشار نحوه، والقديم سبحانه لا جارحة له؛ فيصح الإيماء والإشارة بها منه فبطل عندهم أن تصح المو اضعة على اللغة منه تقدت أسماؤه. قالوا: ولكن يجوز أن ينقل الله اللغة التي قد وقع التواضع بين عباده عليها، بأن يقول: الذي كنتم تعبرون عنه بكذا عبروا عنه بكذا، والذي كنتم تسمونه كذا ينبخي أن تسموه كذا وجواز هذا منه سبحانه كجوازه من عباده، ومن هذا الذي في الأصوات ما يتعاطاه الناس الآن من مخالفة الأشكال في حروف المعجم، كالصورة التي توضع للمعميات و التر اجم، و على ذلك أيضًا اختلفت أقلام ذوي اللغات، كما اختلفت أنفس الأصوات المرتبة على مذاهبهم في المو اضعات، وهذا قول من الظهور على ما نر اه. إلا أنني سألت يومًا بعض أهله، فقلت: ما تتكر أن تصح المواضعة من الله تعالى، و إن لم يكن ذا جارحة بأن يحدث في جسم من الأجسام خشبة أو غير ها، إقبالًا على شخص من الأشخاص وتحريكًا لها نحوه ويحدث ويسمع في نفس تحريك الخشبة نحو ذلك الشخص صوتًا يضعه اسمًا له ويعيد حركة تلك الخشبة نحو ذلك الشخص، دفعات مع أنه ـعز اسمهـ قادر على أن يقنع في تعريفه ذلك بالمرة الواحدة؛ فتقوم الخشبة في هذا الإيماء، و هذه الإشارة مقام جارحة ابن آدم في الإشارة بها في المواضعة. وكما أن الإنسان أيضًا قد يجوز إذا أر اد المواضعة أن يشير بخشبة نحو المر اد المتواضع عليه فيقيمها في ذلك مقام يده، لو أر اد الإيماء بها نحوه، فلم يجب 
عن هذا بأكثر من الاعتر اف بوجوبه ولم يخرج من جهته شيء أصلًا فأحكيه عنه وهو عندي وعلى ما تراه الآن لازم لمن قال بامتتاع مواضعة القديم تعالى لغة مرتجلة غير ناقلة لسانًا إلى لسان فاعرف ذلك.

وذهب بعضهم إلى أن أصل اللغات كلها إنما هو من الأصوات المسموعات، كدوي الريح، وحنين الرعد، وخرير الماء، وشحيح الحمار، ونعيق الغر اب، وصهيل الفرس، ونزيب الظبي ونحو ذلك، ثم ولدت اللغات عن ذلك فيما بعد وهذا عندي وجهُ صالح، ومذهبٌ متقبَّ، و اعلم فيما بعد، أنني على تقادم الوقت دائم التنقبر والبحث عن هذا الموضع فأجد الدواعي والخوالج قوية التجاذب لي، مختلفة جهات التغول على فكري؛ وذلك أنني إذا تأملت حال هذه اللغة الثريفة، الكريمة اللطيفة، وجدت فيها من الحكمة والدقة، والإرهاف و الرقة، ما يملك عليَّ جانب الفكر، حتى يكاد يطمح به أمام غلوة السِّحر، فمن ذلك ما نبه إليه أصحابنا رحمه الله ومنه ما حذوته على أمثلتهم، فعرفت بتتابعه و انقياده، وبعد مر اميه و آماده، صحة ما وفقو التقديمه منه، ولطف ما أسعدوا به، وفرق لهم عنه و انضاف إلى ذلك وارد الأخبار المأثورة بأنها من عند الله جل وعز، فقوي في نفسي اعتقاد كونها توقيفًا من الله سبحانه وأنها وحي، ثم أقول في ضد هذا: كما وقع لأصحابنا ولنا، وتتبهوا وتتبهنا على تأمل هذه الحكمة الر ائعة الباهرة، كذلك لا ننكر أن يكون الله تعالى قد خلق من قبلنا، وإن بَعُدَ مداه عنا، من كان ألطف منا أذهانًا، وأسرع خو اطر وأجرا جنانًا؛ فأقف بين تَنْن الخلتين حسيرًا و أكاثر هما فأنكفئ مكثورًا، و إن خطر خاطرٌ فيما بعد، يعلق الكف بإحدى الجهتين، ويكفُها عن صاحبتها، قلنا به، وبالهه التوفيق". [25]

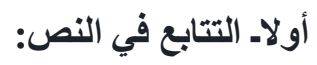
نقل إلينا ابن جني في هذا النص رؤيته في قضية أصل اللغة، والمتأمل في النص يجد الوحدة الموضوعية والفكرية متحققة فيه، وقد شكلت الجمل سلسلة من البُنى اللغوية المتماسكة من خلال توظيف روابط التتابع، وفي مقدمتها روابط العطف، يعمل العطف على تقوية الصلة المعنوية بين المعطوف و المعطوف عليه وزيادة الاقتران بينهما، حتى يكون النص كالكلمة الواحدة. [17] وقد حشد ابن جني في نصسه معظم روابط العطف. حالات العطف في النص: تعددت وتتوعت حالات العطف في النص مابين عطف بالحروف مثل: الواو و الفاء وثم وبل ولكن و غيرها، و عطف بالعبار ات والألفاظ. أـ حالات الواو، الفاء، ثث: تفيد الواو في الغالب مطلق الجمع والتشريك في الإعراب، ولا يشترط فيها الترثيب، وهي أكثر روابط العطف ورودا في النصوص لأنها تقترن بكثير من الحروف مثل: لا، لكن، إمَّا وغير ها، وكذلك الجمل في النصوص تربطها علاقات لفظية ومعنوية، وقد تتكرر ولكي تتسق وتتسجم لابد من ربطها بالو او. قال ابن جني: "إن الله سبحانه عَلَّمَ آدمَ أسماءَ جميع المخلوقات بجميع اللغات العربية والفارسية، والسريانية والعبر انية والرومية وغير ذلك من سائر اللغات" ربطت الواو بين (العربية، الفارسية، السريانية، العبرانية) وجمعتها في خيط واحد منسق وأفادت الترتيب، وفي 
قوله: "تفرقو ا في الدنيا، وعَلق كل منهم بلغةٍ من تلك اللغات" ربطت الواو بين الجملتين وبينت اتصالهما في المعنى مفيدة التعقيب، وفي قوله: "إنما هو تواضع واصطلاح، لا وحي وتوقيف" جمعت الواو بين العبار ات: (تو اضع، اصطلاح، نوقيف) مفيدة الترتيب كذللك، كما ربطت الواو بين الفقرة الأولى والثانية في النص. وقد وردت الو او كثير ا في النص من ذلك قول ابن جني: "وهذا لا يتناول موضع الخلاف، وذلك أنه قد يجوز أن يكون تأويله: أَقَدَرَ آدم على أن واضع عليها، وهذا المعنى من عند الله سبحانه" وقوله: " وليس بمدَّعٍ أن هذا باب مسنور ولا حديث غير مشهور ... لفثوه فيهم وكثرة جريانه على ألسنتهم" وقوله: "وذهب بعضهم إلى أن أصل اللغات كلها إنما هو من الأصوات المسموعات كدوي الريح، وحنين الرعد، وخرير الماء، وشحيح الحمار، ونعيق الغراب، وصهيل الفرس، ونزيب الظبي ونحو ذلك". جاءت الواو في الأمنلة أعلاه في مواضع لا تقبل غير ها من حروف العطف، فأدت الواو وظيفة الترتيب في قوله: "وهذا لا يتناول موضع الخلاف، وذللك أنه قد يجوز أن يكون تأويله: أَقْدَرَ آدم على أن واضع عليها، وهذا المعنى من عند الله سبحانه" وفي قوله: "هي من عند الله واحتج..." أفادت الواو الترتيب والتعقيب فالحجة جاءت تابعة مؤكدة لكونها من عند الله، وقوله: "كدوي الريح ..." مكنّت الواو القائل من جمع معظم عناصر فكرته في نرتيب وتتابع دقيق و إيجاز واضح. كذلك جاءت الواو مقترنة باسم الإشارة بكل أنواعه كما في قوله: "وذلك أنه قد يجوز أن يكون تأويله" وأيضا أفادت الترتيب بين عناصر الفكرة. نخلص إلى أن الواو وردت داخلة على الاسم والفعل والحرف، مما يؤكد مرونة واو العطف ووجودها في كل مفاصل الكلام، وفي هذا النص نجد الواو الرابط التتابعي الأساس بين أجز اء النص و المحقق الفاعل لتماسك و انسجام النص. وتفيد الفاء الترتيب أي: أن المعطوف يحدث أولا ويليه المعطوف عليه، والتعقيب ومعناه أن المعطوف واقعا بعد المعطوف عليه مباثرة، والسبيية أي: المعطوف منسببا عن المعطوف عليه، ويضبط هذه الإفادة السياق بشقيه اللغوي و المقامي. قال ابن جني: "و عَلق كل منهم بلغةٍ من تلك اللغات فغلبت عليه و اضمحل عنه ما سواها" دلت الفاء على جملة (فغلبت عليه...) و أفادت الترتيب و التعقيب لأن التعلق باللغة سابق على غلبتها وتمكنها ممن تعلق بها فحدث التعلق أو لا ثم الغلبة ثانيا. وقال:"ثم لنعدْ فلنقل في الاعتلال لمن قال بأن اللغة لا تكون وحيًا" الفاء في المثال السابق استثنافية وهي تربط بين جملتين لا علاقة بينهما في الإعراب ولكن توجد بينهما علاقة في الموضوع. وقال ابن جني:" كأن يجتمع حكيمان أو ثلاثة فصاعدًا، فيحتاجوا إلى الإبانة عن الأشياء المعلومات، فيضعو الكل واحد منها سمةً ولفظًا، إذا ذُكر عُرف به ما مسماه، ليمتاز من غيره" الفاء الواردة في المثال أعلاه (فيحتاجوا، فيضعو ا...) أفادت الترتيب و التعقيب. وفي قوله: "وإن أر ادو اسمة عينه أو يده أثناروا إلى ذلك فقالوا: يد، عين، رأس، قدم..." الفاء في (فقالو ...) ربطت بين الثرطو الجواب لذلك الفاء الثرطية من أهم روابط التتابع والتماسك في النصوص و إذا رجعت إلى (الفاء) في النص تجدها وردت كثير ا مفيدة الترتيب و التعقيب و الاستئناف ولم تأتِ لمعان أخرى إلا نادر ا كالثرطية. 
أمَّا (ثم) فتفيد الترتيب والتعقيب مثل الفاء مع التراخي في الزمن، ولكن الزمن قد يكون حقيقي أو نفسي وقد يطول أو يقصر وفق السياق والأغر اض البلاغية المختلفة. قال ابن جني: "وغير ذلك من سائر اللغات؛ فكان آدم وولده يتكلمون بها، ثم إن ولده تفرقوا في الدنيا". استخدم ابن جني الحرف (ثم) ليربط بين الفكرتين: "فكان آدم وولده بتكلمون بها ثم إن ولده تفرقو ا في الدنبا" وضحت الأداة (ثم) الترتيب لأنهم تعلموا اللغات أولا، وظلوا زمنا في موطنه ثانيا ووقع التقرق ثالثا، كما بينت التراخي ومن غير شك أنهم مكثوا زمنا طويلا في موطنهم وبعدها وقع التفرق، لذلك وُفِق ابن جني في اختيار (ثم) التي أضافت مزيدا من التتابع المنطقي المو افق لطبيعة الحدث. وقال في موضع آخر من النص: " ثم لنعذْ فلنقل في الاعتلال لمن قال بأن اللغة لا تكون وحيًا" بعد أن عرض ابن جني رأي وأدلة من قال بأن اللغة وحي من الله، عاد وعرض الرأي الآخر قائلا: " ثم لنعذ..." وهو بذلك يشير إلى وحدة الموضوع وترتيب الأفكار و النظريات، فجاء بنظرية الوحي أو لا و أعقبها بنظرية المواضعة ثانياً، فاستعمل_الأداة (ثم) للترتيب، وكذللك يوجد زمن بين مر اجعة أدلة النظرية الأولى ثم الانتقال إلى الثانية ولا أداة أنسب من التعبير عن هذا الزمن إلا (ثم) التي وردت في نص ابن جني ثثلاثة مرات مفيدة الترتيب و التعقيب ولم ترد لمعنى آخر. ب ـ حالات أو، أم، بل، لكن، لا، حتى: (أو) حرف يعطف المفردات والجمل ويفيد معان تختلف باختلاف التركيب والسياق وهي: الإباحة و الاستثناء والتخيير و التقسيم و الأمر و الطلب و التلعيل والاشتر الك والإضراب، وكل هذه المعاني محكومة بالسياق الذي ورد فيه الكلام، ففي قول ابن جني: " أذكرته واستشهدته أو لم أذكره" أفادت (أو) التخيير والإباحة فيمكنه أن يذكر أو لا يذكر لأن الأمر قد لا يحتاج إلى مزيد من الأدلة بحسب السياق، وفي قوله: "يد عين، رأس، قدم، أو نحو ذلك" جاءت (أو) بمعنى الواو أي ونحو ذلك، فأفادت مطلق العطف، وكثير ا ما تدخل (أو) على كلمة (نحو) فتصبح (أو نحو) و تقيد مزيدا من العطف. أما حرف العطف (لا) فيفيد نفي الحكم من المعطوف و إثباته للمعطوف عليه وكثير ما يسبقها الواو (و لا) كما في المثال: "ولا يريد بذلك أن هذا أمر خفي، فلا يعلمه إلا الله وحده، بل إن ما يحيل فيه على أمر واضح وحال مشهورة" وقع النفي على أنه لا بريد أن الأمر خفي ولكن يريد أنه يمكن أن يعلمه البشر أيضا لأنه و اضح ومشهور. ومثلكه هذين المثالين: "ولبس بمدعٍ أن هذا باب مستور، ولا حديث غير مشهور حتى إنه لا يعرفه أحد إلا الله وحده" "إنما هو نواضع واصطلاح، لا وحي وتوقيف" أفادت (لا) نفي الحكم عن المعطوف و أثنتته للمعطوف عليه. وتدخل (بل) على المفرد وعلى الجملة، فإن دخلت على المفرد وسبقها نفي أو نهي فهي تفيد إثبات الحكم لما قبها و إثبات عكسه لما بعدها، كقولك: (لا تقل شعر ا بل نثرا)، وإن دخلت على الجملة أفادت إبطال المعنى الذي قبلها كما في المثال الآتي: "ولا يريد بذلك أن هذا أمر خفي، فلا يعلمه إلا الهه وحده، بل إن ما يحيل فيه على أمر واضح وحال مشهورة" فالمعنى الذي قبلها غير صحيح و لا يعتد به و إنما الفائدة تأتي بعدها. 
وتكون (لكن) عاطفة إذا دخلت على المفرد وسبقها نفي أو نهي ولم تقترن بالواو، وإن وليها جملة فهي للاستدر الك وليست عاطفة، كما في قوله: "قالوا: ولكن لابد لأولها من أن يكون متو اضعًا بالمشاهدة والإيماء" قالوا: ولكن يجوز أن ينقل الله اللغة التي قد وقع التواضع بين عباده عليها، بأن يقول: الذي كنتم تعبرون عنه بكذا عبروا عنه بكذا" أفادت (لكن) في المثالين الاستدراك ومهدت للابتداء بجملة جديدة وفي هذا أيضا تحقيقا للتتابع. تمكَّن ابن جني من وضع الحروف (أو، لا، لكن، بل) في مو اضعها الصحيحة الأمر الذي أضاف إلى

$$
\text { النص التماسك و التتابع اللفظي و المعنوي الواضح، ولم يرد في النص العطف بـ (حتى و أم). }
$$

ج - حالات التفسير والتمثيل: يوضح كاتب النص فكرته ويشرحها عن طريق التفسير و التمثيل والاستشهاد ويستعل لذللك روابط كثيرة، جاء منها في نص ابن جني قوله: "أي: فإذا كان الله يعلمه فلا أبالي بغيره سبحانه" الأداة (أي) تنبه المتلقي إلى أن مابعدها شرحا وبيانا لما قبلها وتعمل على تتابع الفكرة وتسلسلها. وقال أيضا: "فقالوا: يد، عين رأس، قدم، أو نحو ذلك" الرابط (نحو ذلل) يجعل المنلقي يفكر في المفردات المناسبة التي يمكن إضافتها للتي قبلها وبذلك تساهم الأداة (نحو) في إضافة مزيد من التتابع، وقال: "ويولد منها لغات كثيرة، منها: الرومية و الزنجية وغير هما" الأداة (منها) جاءت بمعنى (مثل) و أفادت التوضيح و التمثيل و الاستشهاد وربطت ما بعدها بما قبلها، وقال: "الذي كنتم تعبرون عنه بكذا عبروا عنه بكذا، والذي كنتم تسمونه كذا ينبغي أن تسموه كذا" و" كالصورة التي توضع للمعميات و التر اجم" قوله: (بكذا، و الكاف الداخلة على كلمة الصورة) أفادتا التمثيل والتوضيح. د ـ حالات الإحالة بالضمير والإشارة: شكلت الضمائر المنصلة والمنفصلة وأسماء الإشارة شبكة منينة من الروابط في النص، وجعلته متتابعا متسقا متماسكا، وذللك لأن الضمير يفسر ويوضح ما يعود إليه، ويحقق بجانب ذلك الإيجاز وكذللك اسم الإشارة يربطنا بالمشار إليه فيزول اللبس ويتضح المعنى. قال: " إلا أن أبا علي رحمه الله قال لي يومًا: هي من عند الله" و"وهذا المعنى من عند الله سبحانه" الضمير (هي) يعود للغة وهي موضوع النص الرئيس، واسم الإشارة (هذا) يحيل على فكرة مذكورة قبله في النص. وفي الأمثلة: " فإذا كان ذلك محتملً غير مستنكر سقط الاستدلال به" "و هذا أيضًا رأي أبي الحسن" " إنها تواضع منه" " فكان آدم وولده يتكلمون بها" "وعَلق كل منهم بلغةٍ من تللك اللغات" " ثم إن ولده تفرقوا في الدنيا" تجد مجموعة من الضمائر وأسماء الإشارة شكلت جسرا من

$$
\text { الإحالات التي جمعت أطر اف الأفكار وكثفت عن المر اد منها. }
$$

ح - حالات الإضافة: تحقق الإضافة مزيدا من الثرح وتتم عبر ألفاظ ورو ابط كثيرة منها قوله: "وذهب بعضهم إلى أن أصل اللغات كلها إنما هو من الأصوات المسموعات" عبارة (وذهب بعضهم) نبهت وأشارت إلى أن هنالك رأي آخر أو نظرية أخرى ينبغي متابعتها ودر استها، وفي هذه الأمثلة: "وأُضيف إلى ذللك وارد الأخبار" أيضًا قال به في بعض كلامه" " وغير ذلك من سائر اللغات" وردت روابط أفادت الإضافة كقوله: (و إضافة إلى، أيضا قال، وغير ذلك) كلها عملت على تقوية أو اصر التماسك بين أجزاء النص. 
1/ اختيار المفردة المناسبة والموضوع يؤدي إلى بيان الفكرة وانسجام الدلالة وحمل المتلقي على المتابعة. وقد نجح ابن جني في اختياره للمفرداته فكلها تتناسب وبحثه عن أصل اللغة، كقوله: "ثم أقول في ضد هذا: كما وقع لأصحابنا ولنا، وتنبهوا وتتبهنا على تأمل هذه الحكمة الر ائعة الباهرة" و "كذللك لا ننكر أن يكون الله تعالى قد خلق من قبلنا، وإن بَعُدَ مداه عنا، من كان ألطف منا أذهانًا، وأسرع خو اطر و أجر أ جنانًا؛ فأقف بين تََْن الخلتين حسيرًا" و "و إن خطر خاطرٌ فيما بعد، يعلق الكف بإحدى الجهتين، ويكفُها عن صاحبتها، قلنا به" المفردات الواردة في الأمثلة المختارة منتقاة بعناية ودر اية وكثفت بجلاء عن موقف ابن جني المتردد في البت في أصل اللغة أهي وحي وإلهام أم مواضعة واصطلاح، فهو لم يقرر بشكل قاطع أي النظريتين أصوب، وكذلك نتناسب وموضوع النص. 2/ التكرار اللفظي أو المعنوي يشد المتلقي ويجدد نشاطه ويحفزه للمواصلة في التلقي. قال ابن جني " وقالوا: إنسان إنسان إنسان..." تكر ار لفظة (إنسان) يتناسب ونظرية المو اضعة وكأنهم أر ادوا التأكيد و إثبات التسمية. 3/ التناسب بين الكلمات وزنا وطو لا بضفي على النص مسحة إيقاعية لطيفة جاذبة. مثل قوله"... أن هذا باب مستور و لا حديث غبر مشهور ... لفشوه فيهم، وكثرة جريانه على ألسنتهم" و"أقرب وأخف وأسهل من تكلف إحضاره" "وأمر في هذا أظهر، وشواهده أكثر و أسير" جاءت في الأمثلة المذكورة عدد من الكلمات المنفقة وزنا وطو لا وبذلك أضافت وقع موسيقي يشد المتلقي على التتابع. ثانياـ الاستتتاج في النص: لم يذكر ابن جني صراحة رأيه في القول بأصل اللغات ولكن أثناء عرضه كان بذكر بعض النتائج مستعملا عبار ات تدل على ذلك منها: "إذ قد ثبت أن المواضعة لا بد معها من إيماء وإشارة للجارحة نحو المومأ إليه والمشار نحوه" قوله: (إذ قد ثبت) عبارة تقود إلى نتيجة وهي أن المو اضعة لابد أن يصحبها الإيماء والإشارة. وقال" ومن هذا الذي في الأصوات ما يتعاطاه الناس الآن من مخالفة الأشكال في حروف المعجم" عبارة (من هذا) أيضا تشير إلى نتيجة جاءت بعدها، وفي قوله: "و هو عندي على ما تر اه الآن لازم لمن قال بامتناع مواضعة القديم تعالى لغة مرتجلة غبر ناقلة لسانًا إلى لسان" تجد عبارة (وهو عندي) إقرار منه بأنه سلَّم بهذه النتيجة ومثله قوله: (هذا عندي) في هذا المثال لأنه أتبعه بقوله: وجه صالح ومذهب متقبل". تخلل عرض ابن جني عدد غير قليل من عبار ات الاستنتاج التي جعلتنا نتابع النص وحدة واحدة متسقة منماسكة. الخاتمة: توصلت الدر اسة إلى النتائج الآتية: 1/ قََّّم ابن جني نصا متماسكا ومتسقا ومتر ابطا لفظا ومعنى. 2/ وزَّع كاتب النص رو ابط التتابع و الاستنتاج نوزيعا صحيحا، إذ جاء بكل رابط في موضعه المناسب له. 3/ اتضح أن معظم روابط الاستتناج تتكون من ألفاظ وعبار ات، بينما تتكون معظم رو ابط التتابع من حروف وقليل من الكلمات. 


$$
\text { 6/4 / و و أسهد الباحثان أن رو ابط التتابع دائما تكون أكثر استعمالا في النصوص من روابط الاستنتاج. }
$$

7/ إن الواو من أكثر روابط العطف ورودا في النصوص لأنه يقترن بكثثر من الحروف مثل: لا، لكن، وغير ها ولأنه لمطلق الجمع ولا يشترط فيه الترتيب أو التعيب. 8/ تبين أن معاني (ثم) أقلَّ من معاني (الواو) و (الفاء) في النص المختار للار اسة. 9 يتحكم السياق بشقيه اللغوي و المقامي في بيان معنى الروابط المختلفة. 


\section{قائمة المراجع والمصادر:}

[1][ابن منظور (ت ات 711/3ه)، لسان العرب، تحقيق أمين محمد عبد الوهاب، ومحمد الصادق العبيدي، دار إحياء التراث العربي بيروت،

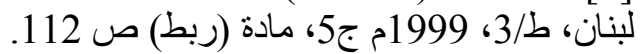

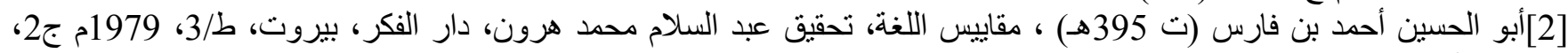

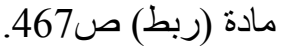
[3][اسماعيل بن حماد الجوهري (ترب (ت 393هـ)، تاج اللغة وصحاح العربية، تحقيق أحمد عبد الغفور عطار، دار العلم للملايين بيروت،

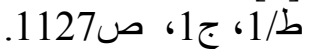

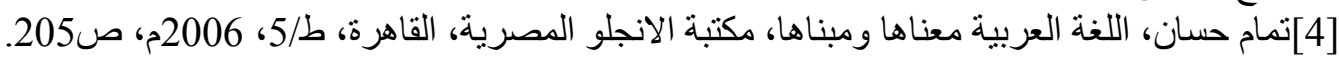

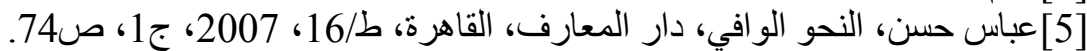

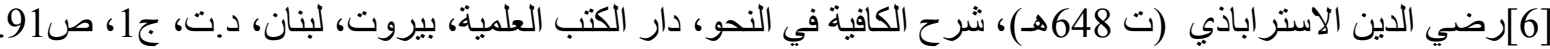

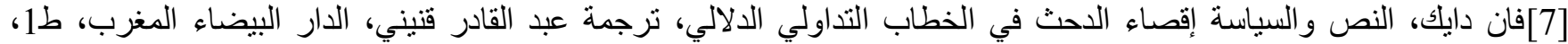

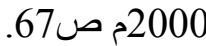

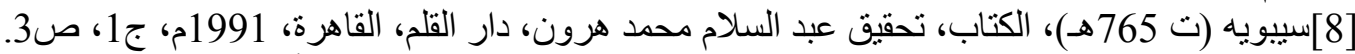

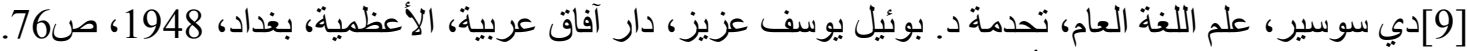

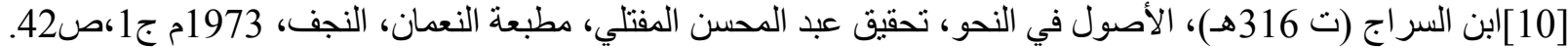

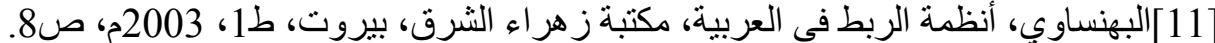

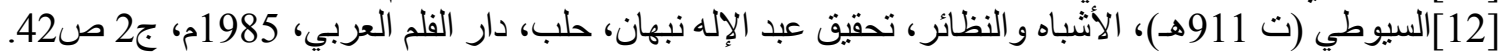

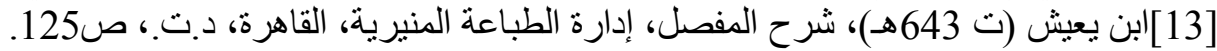

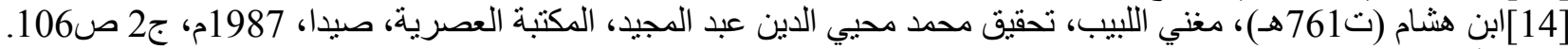

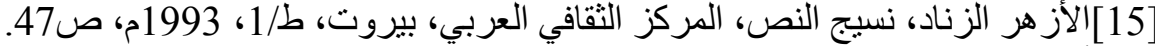

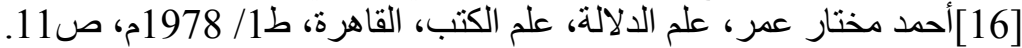

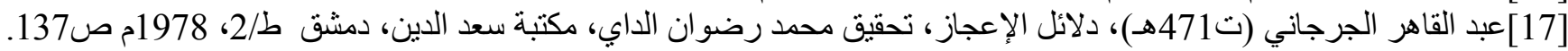

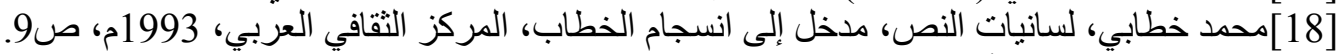

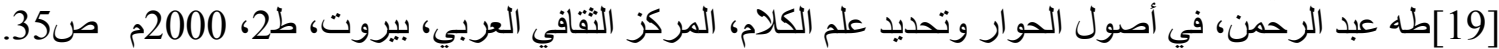

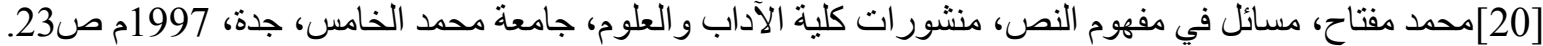

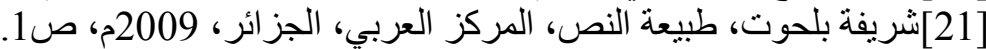

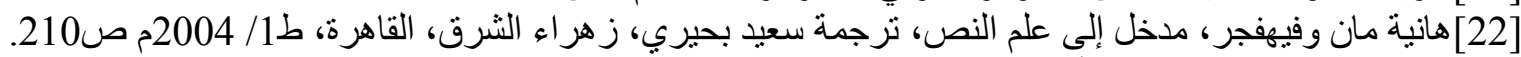

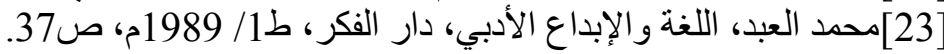

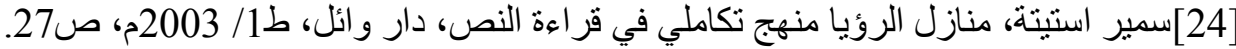

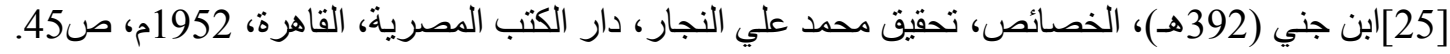

